\title{
Industry Update
}

\section{The latest developments in therapeutic delivery}

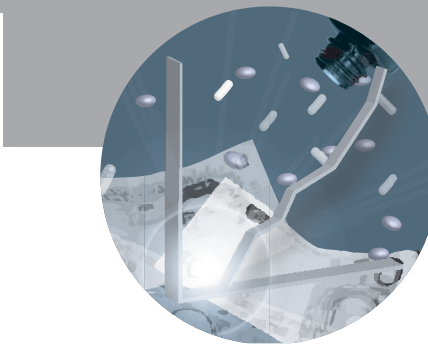

Managing information overload and obtaining a clear overview of the latest events are two of the most common challenges of the post-internet age. For busy scientists, clinicians and drug developers this can be especially difficult, owing to the importance of keeping up-to-date in their field while actually carrying out their daily work. This industry update aims to alleviate this for those working in therapeutic delivery by providing a snapshot of some of the recent events and results in this area. The information contained in this edition covers 20 April to 20 May 2010 , and is based on the contents of company press releases and websites.

\section{Business DeVelopment}

\section{Collaboration agreement:}

Silence Therapeutics \& AstraZeneca

Silence Therapeutics, London, UK [1], and AstraZeneca, London, UK [2], have agreed to a 1-year extension of their existing collaboration on the delivery of siRNA. The aim of this agreement is to develop new and enhanced delivery systems for RNAi therapeutics by leveraging a number of Silence's proprietary lipid and targeting technologies. The financial terms of the agreement, which was originally signed in March 2008, and the extension have not been disclosed. However, both companies retain the right to commercialize the technologies which result from the collaboration. This agreement is independent of the partners' other collaboration on the development of novel RNAi therapeutics against specific disease targets exclusive to AstraZeneca.

\section{Codevelopment agreement:}

\section{Siogen Biotech \& Veeda Clinical Research}

Siogen Biotech, Kuala Lumpur, Malaysia [3], and Veeda Clinical Research, Ahmedabad, India [4], have signed a strategic partnership agreement to develop a nanoparticle formulation of doxorubicin. Under the terms of the agreement Siogen will use its silicon-based nanoparticle technology, Siosomes ${ }^{\circledR}$, to entrap the drug, while Veeda will be responsible for the Phase I and II trials. Siosomes vesicles are composed of one or more organosilicon lipid bilayers. Like liposomes they can entrap a variety of molecules, while, if desired, targeting agents and other molecules can be attached to the two functional groups not involved in bilayer formation.

\section{Codevelopment agreement:}

\section{Antares Pharma \& Uman Pharma}

Antares Pharma, Ewing, New Jersey, USA [5], and Uman Pharma, Quebec, Canada [6], have formed a strategic alliance to develop and commercialize Antares' VIBEX ${ }^{\mathrm{TM}}$ MTX in the USA and Canada. VIBEX MTX is a pressure-assisted injection device, containing methotrexate (MTX) for the treatment of rheumatoid arthritis and related autoimmune conditions. Antares will lead the clinical development program, US regulatory submissions and retain rights to market the VIBEX MTX product outside of Canada, while Uman will perform formulation development, manufacturing activities and supply MTX in prefilled syringes to Antares for sale in the USA. As part of the deal Uman received an exclusive license to commercialize the product in Canada. The two companies will work together to achieve commercialization in other territories.

\section{Finance agreement:}

Hercules Technology Growth Captial

\& Alexza Pharmaceuticals

On 5 May 2010 it was announced that Hercules Technology Growth Capital, Palo Alto, California, USA [7], had provided Alexza Pharmaceuticals, Mountain View, California, USA [8], with a $\$ 15$ million working capital loan. This loan will be used for capital equipment and working capital purposes and will assist in the commercialization of Alexza's lead program, AZ-004 (Staccato ${ }^{\circledR}$ loxapine). Alexza's technology, the Staccato system, vaporizes unformulated drug to form a condensation aerosol which, when inhaled, allows for rapid systemic drug delivery. A New Drug Application for AZ-004, which is being developed for the treatment of agitation in schizophrenic or bipolar disorder patients, was submitted to the US FDA in December 2009.

\section{Regulations \& Approvals}

Allergan

At their May meeting the European Medicines Agency's (EMA) Committee for Medicinal Products for Human Use (CHMP) [9] adopted a

Louise
Rosenmayr-Templeton
Tower Pharma Consulting,
Auhofstrasse 197/I0,
Vienna II30, Austria
Tel.: +43 I600 3464
Fax: +43 I600 3464
E-mail: louise.templeton@
towerpharmacon.com




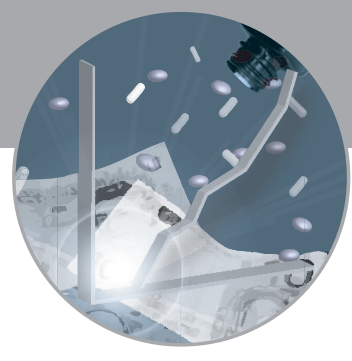

positive opinion on Allergan's Ozurdex ${ }^{\mathrm{TM}}$ intravitreal implant $[10,11]$. This product is already approved in the USA for the treatment of macular odema following branch or central retinal vein occlusion. It contains $0.7 \mathrm{mg}$ dexamethasone in Allergan's solid polymer drug delivery system, Novadur ${ }^{\mathrm{TM}}$. The poly(lactide-co-glycolide) polymer implant is preloaded into a specially designed applicator to facilitate its direct injection into the vitreous humor. The CHMP's recommendation is based on the results of two multicenter, doublemasked, sham-controlled studies which showed that $20-30 \%$ of patients gained three or more lines of vision on the eye chart within 1-2 months in comparison with $7-12 \%$ of those who received sham injections. This improvement lasted around 1-3 months.

\section{Amylin Pharmaceuticals, Eli Lilly \& Alkermes}

Amylin Pharmaceuticals, San Diego, California, USA [12], Eli Lilly, Indianapolis, USA [13], and Alkermes Waltham, Massachusetts, USA [14] announced on 6 May 2010 that the FDA has classified the complete response to their jointly developed Bydureon ${ }^{\mathrm{TM}}$ product as a class 2 resubmission, and assigned a new Prescription Drug User Fee Act action date of 22 October 2010. Bydureon is a once-weekly formulation of the glucagon-like peptide-1 receptor agonist, exenatide, currently marketed as Byetta ${ }^{\mathrm{TM}}$, for the treatment of Type 2 diabetes. It was first filed with the FDA in May 2009 and the complete reponse letter pertained to product labeling, risk evaluation and mitigation strategy (REMS) and clarification of existing manufacturing processes. The formulation is based on Alkermes Medisorb ${ }^{\circledR}$ technology, which achieves sustained release through entrapment of the active within poly(lactide-co-glycolide) microparticles. If approved, Bydureon will facilitate patient convenience by reducing injection frequency from twice daily to once weekly.

\section{European Paediatric Research Network} The EMA has taken another step forward to setting up the European Paediatric Research Network (EnprEMA) [15]. This network has the goal of fostering high quality, ethical research in pediatric populations by a number of mechanisms including improving the pharmaceutical industry's access to expertise in this area. It will be composed of existing research networks, investigators and centers with specific experience in conducting clinical trials in children. Membership will be limited to those meeting defined criteria with respect to their research experience and ability, organization and processes, scientific competencies and capacity to provide expert advice, quality management, training and educational capacity to build competences, and public involvement. On 12 May 2010 the EMA announced that the operational structure of the EnprEMA had been agreed, and requested that parties interested in joining start the selfassessment process against the aforementioned criteria. The deadline for self-assessment is 31 July 2010 and the results will be made public by the Agency and the participating groups.

\section{Clinical Trials}

\section{Taspoglutide}

On 29 April 2010 Ipsen, Paris, France [16], announced that its partner, Roche, Basel, Switzerland [17], had disclosed that their onceweekly long-acting glucagon-like peptide-1 analog, taspoglutide, has reached its primary end point with respect to HbA1c levels in the T-emerge 3 trial. This Phase III study assessed the efficacy of taspoglutide in patients with Type 2 diabetes mellitus inadequately controlled with metformin plus pioglitazone, compared with placebo after 24 weeks of treatment. It is one of eight T-emerge studies that have been or are being undertaken to assess the safety and efficacy of this compound. Data from T-emerge 1, 2, 4, 5 and 7 were released earlier this year. Taspoglutide, which was discovered by Ipsen and licensed to Roche, has structural modifications that provide it with intrinsic controlled release properties without the need for the active to be entrapped within a polymer or lipid matrix.

\section{EndoTag ${ }^{\mathrm{TM}}-1$}

On 6 May 2010 MediGene, Martinsried, Germany [18], released initial promising results from a Phase II trial of its candidate, EndoTag-1, in triple receptor-negative breast cancer. The trial, in 140 patients at 30 different centers, assessed $44 \mathrm{mg} / \mathrm{m}^{2}$ EndoTag-1 twice weekly versus $22 \mathrm{mg} / \mathrm{m}^{2}$ EndoTag-1 plus $70 \mathrm{mg} / \mathrm{m}^{2}$ paclitaxel once weekly versus $90 \mathrm{mg} / \mathrm{m}^{2}$ paclitaxel once weekly. Data gathered to date point to an average $59.1 \%$ progression-free survival rate at 16 weeks for the combination therapy compared with one of 48 and $34.2 \%$ for the paclitaxel and EndoTag-1 monotherapies, respectively.

EndoTag-1 consists of paclitaxel embedded in cationic liposomes. These positively charged carriers attach selectively to negatively charged, dividing endothelial cells inside newly formed tumor blood vessels. Therefore, EndoTag-1 targets the entrapped paclitaxel to these cells, 
allowing it to attack them; thus, suppressing angiogenesis, and reducing the potential for further tumor growth.

\section{ORMD-080I}

Another company reporting positive results was Oramed Pharmaceuticals, Jerusalem, Israel [19]. On 6 May 2010 it released the outcome of a Phase IIb clinical trial of its oral insulin capsule, ORMD-0801. This randomized, double-blind, placebo-controlled, multicenter study evaluated the responses of 29 Type 2 diabetes patients to ORMD-0801. These patients were administered insulin-loaded or placebo capsules over a 6-week period.

The study showed that ORMD-0801 was well tolerated and exhibited a positive safety profile. In addition, the percentage of subjects demonstrating clinically relevant reductions in insulin, C-peptide, fasting blood glucose and Hb1Ac levels was always higher in the ORMD-0801 cohort, when compared with the placebo. Furthermore, mean decreases in insulin and C-peptide immunoreactivity levels were found to be statistically significant following the 6-week, once-daily ORMD-0801 treatment period. This would suggest that ORMD-0801 reduces insulin oversecretion in these patients. The Oramed platform technology on which ORMD-0801 is based involves pharmacopoeial and generally regarded as safe excipients that protect the protein during its passage through the GI tract and promote its absorption.

\section{Abraxane ${ }^{\circledR}$}

On 20 May 2010 Abraxis Bioscience, Los Angeles, California, USA [20], reported positive results with Abraxane, its paclitaxel albumin-bound particle suspension for injection, in a Phase II study of patients with advanced pancreatic cancer previously treated unsuccessfully with gemcitabine. The trial showed that at a dose of $100 \mathrm{mg} / \mathrm{m}^{2}$ Abraxane resulted in 58\% of patients achieving 6-month overall survival, with a median survival of 7.3 months and a median progression-free survival of 1.6 months. Five patients remain alive at a median follow-up of 12.7 months, including one patient with stable disease on cycle 15 of therapy. Abraxane is already approved for breast cancer after failure of combination chemotherapy for metastatic disease or relapse within 6 months of adjuvant chemotherapy.

\section{Intellectual Property}

Intezyne

On 22 April 2010 Intezyne, Tampa, Florida, USA [21], announced that the European Patent
Office intends to grant a patent covering a key element of Intezyne's drug delivery technology, the IVECT TM Method. This consists of polymeric micelles formed through the self-assembly of a triblock copolymer consisting of a hydrophobic portion linked through a stimulus-responsive crosslinker to a hydrophilic segment. The watersoluble end of this copolymer can be conjugated to a cell-targeting agent if desired. The crosslinks formed between the copolymer chains help stabilize the vesicles formed. However, in response to the appropriate stimulus, the crosslinks break apart triggering the release of the active.

The technology is already covered by seven patents both in the USA and worldwide. The granting of this European patent will allow greater flexibility and versatility with respect to the amount of hydrophobic material that can be encapsulated. The company has two candidates at the advanced preclinical stage, IT-141 and IT-143, for the treatment of colorectal cancer and solid tumors, respectively.

\section{SCOLR Pharma}

May was a successful month for SCOLR Pharma, Bothell, Washington, USA [22]. On 3 May 2010 it was announced that the United States Patent and Trademark Office (USPTO) had issued a notice of allowance for SCOLR's US Patent Application No. 11/906,303 for a method of forming a tablet. Furthermore, on 6 May 2010 the company released a statement that it had entered into an agreement with RedHill Biopharma Ltd of Redhill, Israel, granting RedHill the worldwide rights to market and sell ondansetron tablet formulations based on SCOLR's extended delivery platform, CDT ${ }^{\circledR}$. The technologies in this platform control drug release through matrix erosion, changes in gel thickness, electrolyte ionization and ionic interactions.

The patent, once issued, will provide SCOLR with patent protection for the blending and tableting process currently used in its novel extended release ibuprofen formulation and analogous processes for other actives susceptible to tackiness. It adds to the firm's existing patent portfolio that includes patents covering its dual polymer, electrolyte and amino acid platforms.

\section{Mystic Pharmaceuticals}

Mystic Pharmaceuticals, Austin, Texas, USA [23], have been granted a US patent (US7,669,597) for its proprietary unit-dose blister technology for the packaging of lyophilized drugs and biologics. This is a key component of Mystic's VRx2 $2^{\mathrm{TM}}$ platform that enables the pre-packing of freezedried actives in novel intranasal or ophthalmic 


\section{NeWS \& ANALYSIS | INDUSTRY UPDATE}

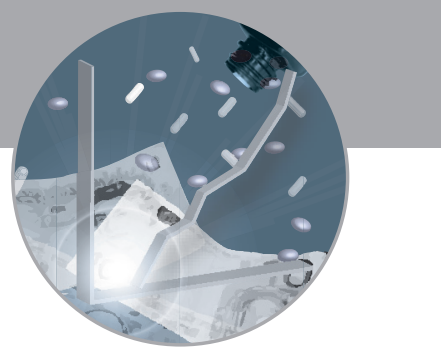

delivery systems, which allow patients to reconstitute the blisters automatically and administer the dose at the push of a button.

Financial \& competing interests disclosure The author has no relevant affiliations or financial involvement with any organization or entity with a financial interest in or financial conflict with the subject matter or materials discussed in the manuscript. This includes employment, consultancies, honoraria, stock ownership or options, expert testimony, grants or patents received or pending, or royalties.

No writing assistance was utilized in the production of this manuscript.

\section{Websites}

1 Silence Therapeutics plc www.silence-therapeutics.com

2 AstraZeneca www.astrazeneca.com

3 Siogen Biotech www.siogen.com

4 Veeda Clinical Research ${ }^{\circledR}$ www.veedacr.com

5 Antares Pharma, Inc. www.antarespharma.com

6 Uman Pharma Inc. www.umanpharma.com

7 Hercules Technology Growth Capital, Inc. www.htgc.com

8 Alexza Pharmaceuticals, Inc. www.alexza.com
9 European Medicines Agency www.ema.europa.eu

10 Allergan Inc. www.allergan.com

11 Ozurdex ${ }^{\mathrm{TM}}$ www.ozurdex.com

12 Amylin Pharmaceuticals Inc. www.amylin.com

13 Eli Lilly and Company www.lilly.com

14 Alkermes, Inc. www.alkermes.com

15 European Medicines Agency EU Paediatric Network www.ema.europa.eu/htms/human/ paediatrics/network

16 Ipsen www.ipsen.com
17 F Hoffmann-La Roche Ltd www.roche.com

18 Medigene AG www.medigene.com

19 Oramed Pharmaceuticals, Inc. www.oramed.com

20 Abraxis BioScience, LLC www.abraxisbio.com

21 Intezyne, Inc. www.intezyne.com

22 SCOLR Pharma, Inc. www.scolr.com

23 Mystic Pharmaceuticals, Inc. www.mysticpharmaceuticals.com 